\title{
Testosterone increases bradykinin-induced relaxation in the coronary bed of hypertensive rats
}

\author{
Juan Carlos Arapa-Diaz', Wender do Nascimento Rouver (D1, Jéssyca Aparecida Soares Giesen (D1, \\ Marcela Daruge Grando², Lusiane Maria Bendhack² and Roger Lyrio dos Santos \\ 1Department of Physiological Sciences, Health Sciences Center, Federal University of Espirito Santo, Vitoria, Brazil \\ 2Department of Physics and Chemistry, Faculty of Pharmaceutical Sciences from Ribeirão Preto, University of São Paulo, São Paulo, Brazil \\ Correspondence should be addressed to R L dos Santos: rogerlyrio@hotmail.com
}

\begin{abstract}
Physiological or supraphysiological levels of testosterone appear to be associated with the development of risk factors for cardiovascular diseases such as hypertension, as this hormone modulates the release of endothelial factors. However, its actions are still controversial, especially in the coronary circulation of hypertensive animals. This study was designed to assess the effects of testosterone treatment (T) on endotheliumdependent coronary vascular reactivity in orchiectomized SHR. The animals were divided into SHAM, orchiectomized (ORX), ORX+T and ORX+T+aromatase inhibitor (AI). All treatments lasted 15 days. Blood pressure (BP) was measured. Dose-response curves to bradykinin (BK) were constructed using the Langendorff technique, followed by inhibition of endothelium mediators (NO, prostanoids, EETs) and potassium channels. The intensity of eNOS, COX-1, COX-2, Akt, and gp91 phox protein expression was quantified by Western blotting. BP was elevated in SHAM, ORX+T, and ORX+T+Al groups. However, we did not observe differences in the ORX group. Baseline coronary perfusion pressure (CPP) remained unaffected. Orchiectomy did not change the BK-induced relaxation compared to the SHAM group, whereas testosterone treatment increased it. This response was diminished in the absence of NO, prostanoids, and EETs in the SHAM and ORX groups, while in ORX+T group the relaxation was diminished only in the absence of $\mathrm{NO}$ and EETs. There was no difference in eNOS, COX-1, COX-2, and gp91 phox protein expression, though Akt expression was increased in ORX and ORX+T groups. These results show that testosterone treatment can modulate endothelial function, especially in the coronary circulation under hypertension conditions, via NO and EETs pathways.
\end{abstract}

\section{Key Words}

- coronary vascular bed

- orchiectomy

- testosterone replacement therapy

- endothelium-dependent hyperpolarization
Journal of Molecular Endocrinology (2020) 65, 125-134

\section{Introduction}

Cardiovascular diseases (CVDs) are the major cause of death worldwide, being projected to account more than 23 million deaths by 2030 (Benjamin et al. 2018). Hypertension is considered one of the most prevalent risk factors for CVDs, especially coronary artery disease (MacMahon et al. 1990, Vasan et al. 2001, Chobanian et al. 2003, Dregan et al. 2013, James et al. 2014). The greater incidence of hypertension and cardiovascular 
diseases in men and postmenopausal women compared to premenopausal women points to the female sex hormone estrogen having a protective vascular effect (Farhat et al. 1996, Benjamin et al. 2018), whereas testosterone appears to exacerbate the development of CVDs (Adams et al. 1995). It is known that the withdrawal of male sex hormones is associated with an improvement in endothelial function in adult men (Mark Herman et al. 1997), with testosterone therapy having been associated with detrimental effects (Vigen et al. 2013). However, clinical and epidemiological studies of the relationship between testosterone and CVDs are controversial, for testosterone treatment in men with low levels of this androgen was associated with mortality decrease (Shores et al. 2012). In addition, low testosterone levels are associated with an increased risk of death from CVDs (Haring et al. 2012). Clinically, male hypogonadism (Buvat et al. 2013) shows low testosterone levels and may lead to hypertension (Svartberg et al. 2004), suggesting that the testosterone/hypertension relationship is not completely clear, particularly as to its influence in coronary vascular reactivity.

Classical (genomic or nuclear) actions of testosterone are represented by the interaction of this hormone with the androgen receptor (AR), a member of the superfamily of nuclear receptors activated by ligands that, once stimulated, acts as a transcription factor (Mangelsdorf \& Evans 1995). It is also known that testosterone can act through a rapid, non-genomic (extra-nuclear) responses on the vascular system. These actions may involve the interaction between the hormone and AR (Deenadayalu et al. 2012) but also occur independently of its classical receptor (Jones et al. 2004). These actions may begin both in the plasma membrane and in the cytoplasm, generally raising the concentration of intracellular calcium and activating kinase proteins (Deenadayalu et al. 2012).

In the cardiovascular system, testosterone is able to relax rat aortic rings (Bucci et al. 2009) and pig coronary artery (Deenadayalu et al. 2001), being also known to directly modulate vascular smooth muscle in a rapid, non-genomic manner (Deenadayalu et al. 2001, Bucci et al. 2009). Testosterone has been also shown to promote relaxation in coronary arteries through ionic flow mediated by potassium channels (Deenadayalu et al. 2001) and calcium channels (Montaño et al. 2008).

In addition to the important role of testosterone by acting directly on blood vessels, studies have also focused on demonstrating the effects of testosterone deprivation in the cardiovascular system. Orchiectomy can reduce the expression of voltage-dependent potassium channels in rat aorta, which can be reversed through androgen replacement (Zhou et al. 2008). In a previous study, we showed that testosterone replacement therapy was able to prevent damage in coronary vascular reactivity caused by orchiectomy-induced hormonal deficiency in normotensive rats (Rouver et al. 2015). Taken together, the aforementioned findings attribute to testosterone a possible protective action on the cardiovascular system. However, the mechanisms by which this hormone modulates coronary vascular reactivity when induced by an endothelium-dependent vasodilator agonist (bradykinin), remain to be described. Our hypothesis is that testosterone treatment could modulate endothelial function in isolated heart under hypertension conditions. Thus, this study was designed to assess the effects of testosterone treatment on endothelium-dependent coronary vascular reactivity in orchiectomized spontaneously hypertensive rats (SHR).

\section{Materials and methods}

\section{Animal procedure}

Male SHR with 8 weeks old (200-300 g) were used. The animals were supplied by the Health Sciences Center of the Federal University of Espirito Santo. All procedures were conducted in accordance with recommendations in the Brazilian Guidelines for the Care and Use of animals for the Scientific Purpose and Didactics and the Guidelines Euthanasia Practice and approved by the Institutional Ethics Committee for the Use of Animals (CEUA-UFES, protocol \# 062/2017). The animals were maintained in the group (four animals per cage) with free access to water and food (Nuvilab CR-1), under controlled conditions of temperature $\left(22-24^{\circ} \mathrm{C}\right)$ and humidity $(40-60 \%)$, with a $12 \mathrm{~h}$ light:12 $\mathrm{h}$ darkness cycle. The animals were randomly divided into four experimental groups: control (SHAM), orchiectomized (ORX), orchiectomized and treated with testosterone $(\mathrm{ORX}+\mathrm{T})$, and orchiectomized and treated with testosterone plus aromatase inhibitor $(\mathrm{ORX}+\mathrm{T}+\mathrm{AI})$.

After anesthesia with ketamine $(70 \mathrm{mg} / \mathrm{kg}$, i.p.) and xylazine $(10 \mathrm{mg} / \mathrm{kg}$, i.p.), the animals were fixed with surgical tape over a surgical bed. Before incision, disinfection of the testicular sac was performed with iodized alcohol. Surgery was performed through an incision in the midline of the testicular sac. After exposure of the testicles, the tunica vaginalis was opened, and spermatic cord was ligated and the testes were removed. The incision was closed and the animals received antibiotic (Enrofloxacin, $10 \mathrm{mg} / \mathrm{kg}$, i.m., Chemitec ${ }^{\circledR}$, São Paulo, Brazil), and analgesic (Flunixin meglumine, $2.5 \mathrm{mg} / \mathrm{kg}$ i.m., Chemitec $\left.{ }^{\circledR}\right)$. The control group underwent 
sham surgery (SHAM), except that the testicles were not removed.

Testosterone replacement (bioidentical testosteroneIMAFAR) was performed for 15 days via subcutaneous injection of a dose of $0.5 \mathrm{mg} / \mathrm{kg} / \mathrm{day}$, mimicking a physiological concentration, as previously described (Moysés et al. 2001). For groups that did not receive testosterone treatment, the same volume of vehicle (sunflower oil) was administered (Moysés et al. 2001). The group that was treated with anastrozole (AI, $0.1 \mathrm{mg} / \mathrm{kg}$ / day, diluted in saline solution at $0.9 \%$ ) received it orally, in a maximum volume of $0.2 \mathrm{~mL}$ (Altintas et al. 2010). The animals treated with testosterone received the first dose on the day of orchiectomy to avoid low hormonal levels post-surgery.

The rats were submitted to an adaptation period ( 3 days) before starting the records. The animals were placed in an external chamber at $37^{\circ} \mathrm{C}$ for $10 \mathrm{~min}$. They were then transferred to a heated chamber (IITC INC/Life Science) at the same temperature, and then a pneumatic cuff was placed in the proximal tail region on which was inflated and deflated automatically. After adaptation for 5 min, the systolic blood pressure (SBP) and diastolic blood pressure (DBP) were recorded. We considered records that variations were not greater than $5 \mathrm{mmHg}$. Records associated with animal movements were discarded (Ibrahim et al. 2006, Fritz \& Rinaldi 2008). The pressure measurements were performed one day before the surgical procedure (day 0 ), and at 7 and 15 days.

\section{Isolated heart preparation (modified Langendorff method)}

The experiments were performed on isolated perfused hearts from male SHR that were anesthetized with ketamine $(70 \mathrm{mg} / \mathrm{kg}$, i.p, $)$ and xylazine $(10 \mathrm{mg} / \mathrm{kg}$, i.p.) and injected i.v. with heparin (100 IU) (Bell et al. 2011). Five minutes after heparin injection, rats were euthanized, and hearts were excised. Analyses of the coronary vascular bed were performed on whole hearts using the Langendorff preparation as previously described (Santos et al. 2010). Briefly, using a Langendorff apparatus (Hugo Sachs Electronics, March-Hugstetten, Germany), the isolated hearts were perfused with modified Krebs solution containing the following (in $\mathrm{mM}$ ): $120 \mathrm{NaCl}, 1.26$ $\mathrm{CaCl}_{2} \cdot 2 \mathrm{H}_{2} \mathrm{O}, 5.4 \mathrm{KCl}, 2.5 \mathrm{MgSO}_{4} \cdot 7 \mathrm{H}_{2} \mathrm{O}, 2 \mathrm{NaH}_{2} \mathrm{PO}_{4} \cdot \mathrm{H}_{2} \mathrm{O}$, $27 \mathrm{NaHCO}_{3}, 1.2 \mathrm{Na}_{2} \mathrm{SO}_{4}, 0.03$ EDTA, and 11.0 glucose. The Krebs solution was equilibrated with a mixture of $95 \%$ oxygen and 5\% carbon dioxide at a controlled pressure of $100 \mathrm{mmHg}$ to bring the $\mathrm{pH}$ to 7.4 .
The hearts were perfused at a rate of $10 \mathrm{~mL} / \mathrm{min}$ with a peristaltic pump (MS-Reglo 4 channels, Hugo Sachs Electronics) and were kept at $37^{\circ} \mathrm{C}$. A fluid-filled balloon was introduced into the left ventricle through a steel cannula connected to a pressure transducer (AD Instrument MLT0380/A Reusable BP Transducer) to measure the isovolumetric cardiac force. The balloon was pressurized by a spindle syringe until it reached a preload of $10 \mathrm{mmHg}$.

The baseline coronary perfusion pressure (CPP) was assessed by means of a pressure transducer (AD Instrument MLT0380/A), connected immediately near the aortic perfusion cannula, through which the coronary bed was perfused, attached to a digital data acquisition system (PowerLab System). LabChart 7.3.1 software was used to read the records obtained by the data acquisition system (ADInstruments). The CPP changes were directly related to changes in vascular resistance. After stabilization of the system for $40 \mathrm{~min}$, the baseline CPP was obtained and a dose-response curve of bradykinin (BK, Sigma) was constructed, which was administered in bolus $(0.1 \mathrm{~mL})$ to increasing concentrations $\left(10^{-10}\right.$ to $\left.10^{-6} \mathrm{M}\right)$ before and after perfusion with $100 \mu \mathrm{M}$ of $\mathrm{N}^{\omega}$-nitro-L-arginine methyl ester (L-NAME, non-specific inhibitor of the enzyme nitric oxide synthase - NOS) or $2.8 \mu \mathrm{M}$ of indomethacin (INDO, non-specific inhibitor of cyclooxygenase - COX), or inhibition combined with $100 \mu \mathrm{M}$ of L-NAME $+2.8 \mu \mathrm{M}$ of INDO or $100 \mu \mathrm{M}$ of L-NAME $+2.8 \mu \mathrm{M}$ of INDO $+0.75 \mu \mathrm{M}$ of clotrimazole (CLOT, CYP epoxygenase inhibitor) or $100 \mu \mathrm{M}$ of L-NAME $+2.8 \mu \mathrm{M}$ of INDO $+0.75 \mathrm{mM}$ of tetrabutylammonium (TBA, non-specific blocker of potassium channels) (Moazed et al. 2009).

All inhibitors were perfused for at least 20 min until the in bolus injection of BK was repeated. The relaxing response was calculated by the following equation:

$$
\Delta(\%)=100-\left(\frac{\mathrm{CPP}_{\text {after infusion }} \times 100}{\mathrm{CPP}_{\text {before infusion }}}\right)
$$

\section{Dissection of the coronary arteries}

The animals were anesthetized with ketamine $(70 \mathrm{mg} / \mathrm{kg}$, i.p.) and xylazine $(10 \mathrm{mg} / \mathrm{kg}$, i.p.) and killed by decapitation. The thorax cavity was opened, the heart was removed and placed in a Petri plate whit a cold Krebs solution modified (in mM): $120 \mathrm{NaCl}, 1.25 \mathrm{CaCl}_{2} \cdot 2 \mathrm{H}_{2} \mathrm{O}$, $5.4 \mathrm{KCl}, 2.5 \mathrm{MgSO}_{4} \cdot 7 \mathrm{H}_{2} \mathrm{O}, 2 \mathrm{NaH}_{2} \mathrm{PO}_{4} \cdot \mathrm{H}_{2} \mathrm{O}, 27 \mathrm{NaHCO}_{3}$, $1.2 \mathrm{Na}_{2} \mathrm{SO}_{4}, 0.03 \mathrm{EDTA}$, and 11 glucose at a $\mathrm{pH} 7.4$ for the dissection procedure. The anterior descending branch of the left coronary artery and the septal branch were 
isolated in a dissection microscope (M900, F. Vasconcelos) and then freed from surrounding cardiac tissue, snapfrozen in liquid nitrogen and stocked at $-80^{\circ} \mathrm{C}$ until use.

\section{Western blotting}

The coronary arteries of each group (SHAM, ORX and ORX+T) were macerated in $25 \mu \mathrm{L}$ of RIPA supplemented with protease and phosphate inhibitors $(65.2 \mathrm{mM}$ Tris-HCl, $154 \mathrm{mM} \mathrm{NaCl}, 1 \% \mathrm{NP}-40,0.25 \%$ sodium deoxycholate, $0.8 \mathrm{mM}$ EDTA, $1 \mathrm{mM}$ PMSF, $10 \mathrm{mM}$ sodium orthovanadate, $100 \mathrm{mM}$ sodium fluoride, $10 \mathrm{mM}$ sodium pyrophosphate and protease inhibitor). The homogenates were centrifuged at $9.5 \boldsymbol{g}$ for $10 \mathrm{~min}$ at $4^{\circ} \mathrm{C}$ for the removal of debris. The protein concentration of the samples was determined by colorimetric method (Bio Rad DC Protein assay). Aliquots of the lysate, containing $20 \mu \mathrm{g}$ of total protein, were mixed with sample buffer to final concentration $1 \mathrm{x}$. They were then boiled for 5 min and applied to the gel. Protein separation was done by electrophoresis on $10 \%$ polyacrylamide gel at $4^{\circ} \mathrm{C}$ for approximately $2 \mathrm{~h}$ at $150 \mathrm{~V}$. The molecular weight standard used was the Prestained Protein Ladder - extra broad molecular weight (Abcam). After electrophoresis, the proteins were electrotransferred to nitrocellulose membrane and blocked with 5\% nonfat milk in TBS-T (0.13 M NaCl, $20 \mathrm{mM}$ Tris, $0.1 \%$ Tween 20 and $\mathrm{pH}$ 7.6) $2 \mathrm{~h}$. The blocking solution was withdrawn and the membranes were washed with TBS-T 36 times for $5 \mathrm{~min}$. They were then incubated with primary antibody diluted in TBS-T with 3\% BSA. Mouse antibody to endothelial NOS (eNOS) (1:1000 dilution, Abcam; ab76198), COX-2 (1:1000 dilution, BD; 603203), gp91phox (1:1000 dilution, Abcam; ab80897) and $\beta$-actin (1:5000; Abcam; ab6276); rabbit antibody to COX-1 (1:1000 dilution, Abcam; ab109025), and Akt (1:1000 dilution, Abcam; ab8805). Membranes were incubated overnight at $4^{\circ} \mathrm{C}$. Six washings of $5 \mathrm{~min}$ were followed with TBS-T. Antimouse (1:2000, Cell Signaling; 7076) or anti-rabbit (1:2000, Santa Cruz Biotechnology; sc-2357) conjugated secondary antibodies were diluted in 1\% BSA and applied to the membrane for $1 \mathrm{~h}$ at room temperature. Then another six washes of $5 \mathrm{~min}$ were made and then the chemiluminescence detection was performed using the luminol reagent (Santa Cruz Biotechnology) followed by exposure to radiographic film. Protein quantification was done by densitometry using ImageJ software (NIH). Protein expression was calculated based on the ratio of the specific density of each protein band vs the corresponding density of $\beta$-actin.

\section{Statistical analysis}

Data analysis was performed with the statistical software GraphPad Prism 7. The data were expressed as the mean \pm s.E.M., $n^{\prime \prime}$ represents the number of animals studied. For each data set, D'Agostino-Pearson omnibus normality test was also performed. The comparisons between the groups were made using the one-way ANOVA. The relaxing response to $\mathrm{BK}$ was calculated by the two-way ANOVA. In all cases, the post hoc Tukey test was used, and a significance level of $P<0.05$ was established.

\section{Results}

\section{Ponderal data}

The body weight was not affected among the studies groups (SHAM, ORX, and ORX+T). The weight of the prostate gland $(\mathrm{mg})$ and seminal vesicle decreased in the ORX group. In addition, the testosterone treatment increased the weight of the prostate and seminal vesicle when compared to ORX group (Table 1).

\section{Non-invasive assessment of blood pressure (BP)}

By the 15th day of follow-up, SBP was found to be elevated - by age, when compared to day 0 - in SHAM animals (from $181 \pm 2$ to $205 \pm 6 \mathrm{mmHg}$ ) and in the groups receiving testosterone treatment, ORX+T (from $179 \pm 3$ to $203 \pm 4 \mathrm{mmHg}$ ) and ORX+T+AI (from $167 \pm 2$ to $213 \pm 3 \mathrm{mmHg}$ ) (Fig. 1A). However, SBP remained

Table 1 Body weight and ratio of weight of glands $(\mathrm{mg})$ with the length of the tibia $(\mathrm{mm})$ in the SHAM, ORX and ORX+T groups after 15 days of treatment with a physiological dose of testosterone.

\begin{tabular}{lll}
\hline Parameter & & $\boldsymbol{n}$ \\
\hline Body weight $(\mathrm{g})$ & & 22 \\
Prostate gland $(\mathrm{mg} / \mathrm{mm})$ & & 22 \\
Seminal gland $(\mathrm{mg} / \mathrm{mm})$ & & 22 \\
\hline
\end{tabular}

\begin{tabular}{c}
\hline SHAM \\
\hline $226 \pm 6$ \\
$6.22 \pm 0.346$ \\
$15.43 \pm 0.869$ \\
\hline
\end{tabular}

\begin{tabular}{c}
\hline $\boldsymbol{n}$ \\
\hline 20 \\
20 \\
20 \\
\hline
\end{tabular}

\begin{tabular}{c}
\hline ORX \\
\hline $209 \pm 7$ \\
$0.87 \pm 0.210^{a}$ \\
$2.68 \pm 0.205^{a}$ \\
\hline
\end{tabular}

\begin{tabular}{c}
\hline $\boldsymbol{n}$ \\
\hline 20 \\
20 \\
20 \\
\hline
\end{tabular}

\begin{tabular}{c}
\hline ORX+T \\
\hline $215 \pm 5$ \\
$3.38 \pm 0.348^{* a, b}$ \\
$7.77 \pm 0.618^{a, b}$ \\
\hline
\end{tabular}

The values are expressed as the mean \pm S.E.M. One-way ANOVA and post-test Tukey were used. a $P<0.05$ vs SHAM group; $P P<0.05$ vs ORX group. 

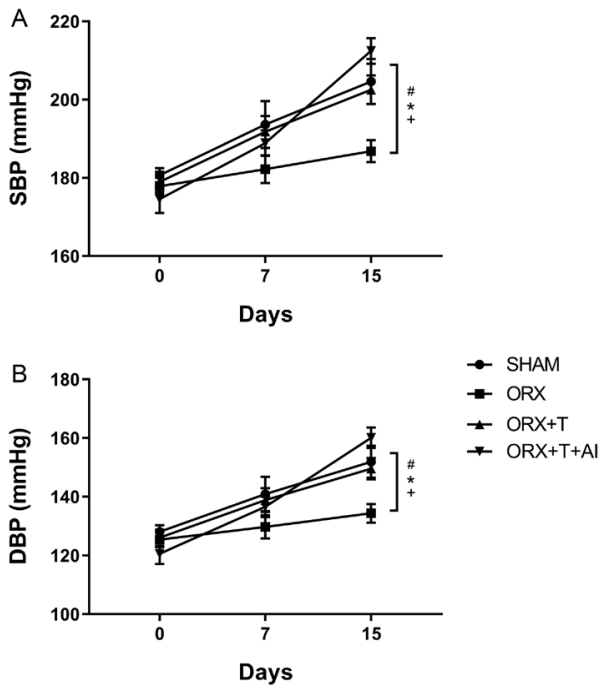

\section{Figure 1}

Blood pressure (BP) assessment in SHR. (A) Systolic blood pressure (SBP) and (B) diastolic blood pressure (DBP). SHAM $(n=13), \mathrm{ORX}(n=18), \mathrm{ORX}+\mathrm{T}$ $(n=22)$ and ORX+T+Al $(n=15)$ groups. Data are expressed as mean \pm S.E.M. Two-way ANOVA and Tukey's post-tests were used. $* P<0.05$ compared to SHAM, $\# P<0.05$ compared to ORX+T and $+P<0.05$ compared to $\mathrm{ORX}+\mathrm{T}+\mathrm{Al}$.

stable in the ORX group, with no differences having been observed after 15 days $(187 \pm 3 \mathrm{mmHg})$ when compared to day $0(178 \pm 2 \mathrm{mmHg}$ ). DBP (Fig. 1B) followed the same response pattern by the end of 15 days of follow-up. We observed that, compared to day 0, DBP was elevated in SHAM (from $128 \pm 2$ to $152 \pm 5 \mathrm{mmHg}$ ), ORX+T (from $126 \pm 3$ to $150 \pm 4 \mathrm{mmHg}$ ) and ORX+T+AI (from $121 \pm 4$ to $160 \pm 4 \mathrm{mmHg}$ ) groups, while remaining stable in the ORX group (from $125 \pm 3 \mathrm{mmHg}$ to $134 \pm 3 \mathrm{mmHg}$ ).

\section{Baseline coronary perfusion pressure (CPP)}

The baseline CPP was not altered in any groups (SHAM, $115 \pm 7$ mmHg; ORX, $114 \pm 5$ mmHg; ORX+T, $110 \pm 3$ $\mathrm{mmHg}$, and ORX+T+AI, $98 \pm 4 \mathrm{mmHg}$ ), as shown in Fig. 2 .

\section{Reactivity of the coronary vascular bed in response to bradykinin (BK)}

Endothelium-dependent vasodilation stimulated by BK was observed in all groups (Fig. 3A). However, orchiectomy did not change the vascular relaxation induced by BK compared to the SHAM group, whereas in ORX+T and ORX+T+AI groups, it was increased. As we did not observe differences in CPP or vasodilation among ORX $+\mathrm{T}$ and ORX+T+AI animals, which would be indicative of the non-conversion of testosterone to

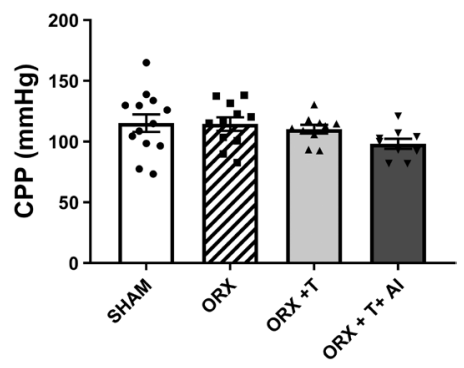

Figure 2

Baseline coronary perfusion pressure (CPP) in SHR. SHAM $(n=13)$, ORX $(n=11), \mathrm{ORX}+\mathrm{T}(n=10)$ and $\mathrm{ORX}+\mathrm{T}+\mathrm{Al}(n=9)$ groups. Data are expressed as mean \pm s.E.M. One-way ANOVA and Tukey's post-tests were used.

estrogen, we opted proceed only with the SHAM, ORX and ORX+T groups.

Perfusion with the NOS inhibitor (L-NAME) attenuated the relaxant response to $\mathrm{BK}$ in all groups when compared to their respective baseline curve to BK. Furthermore, BK-induced vasodilation, under NOS inhibition, was higher in the ORX+T group (Fig. 3B). In the presence of a COX inhibitor, the BK-induced vasodilation response was reduced in SHAM and ORX animals when compared to their respective baseline conditions, with no differences having been observed in the ORX+T group (Fig. 3C). The combined inhibition with L-NAME+INDO decreased the relaxant response to $\mathrm{BK}$ in all groups, with the $\mathrm{ORX}+\mathrm{T}$ group showing a higher response curve to $\mathrm{BK}$ when compared to SHAM or ORX (Fig. 3D). Furthermore, in the presence of CYP or potassium channel inhibitors (CLOT and TBA, respectively), the endothelium-dependent vasodilation response to BK was completely inhibited in all groups, even when combined to NOS and COX inhibitors, confirming the important participation of epoxyeicosatrienoic acids (EETs) and potassium channels in this response in all studied groups (Fig. 3E and F, respectively).

\section{Protein expression}

Figure 4 shows the expression of proteins in coronary arteries in SHR. The expression of eNOS, COX-1, COX-2, gp91phox were not different in any groups studied, as shown in Fig. 4A, B, C and D, respectively. In addition, the expression of Akt, was higher in the ORX and ORX+T groups when compared to the SHAM group (Fig. 4E).

\section{Discussion}

The main finding of our study was that testosterone treatment increased BK-induced vasodilation in the coronary vascular bed of orchiectomized SHR. Nitric oxide 
A

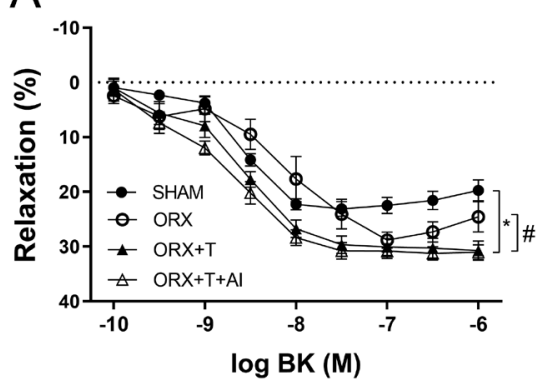

C

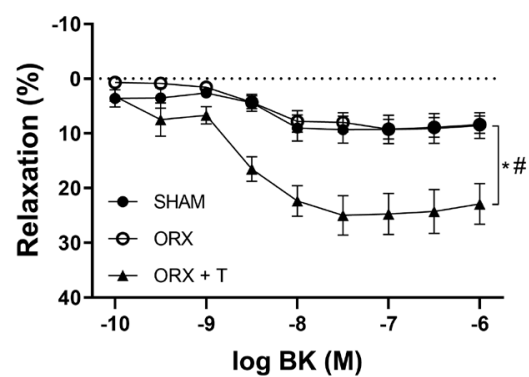

E

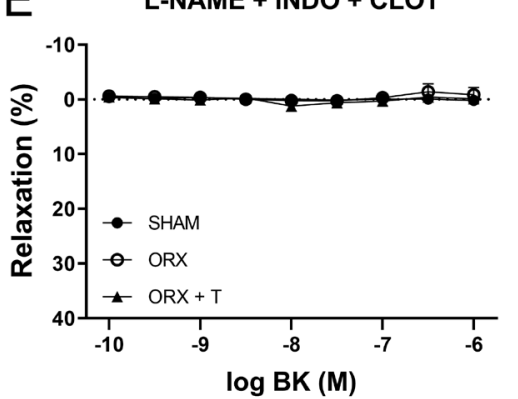

B

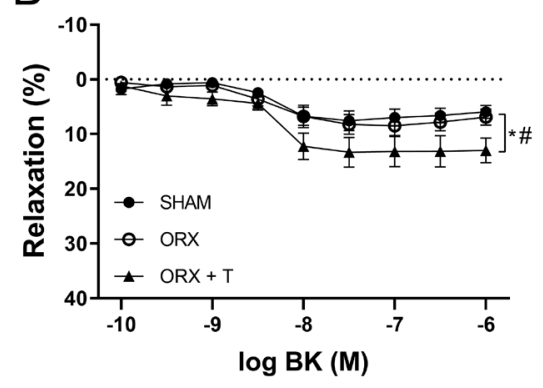

D

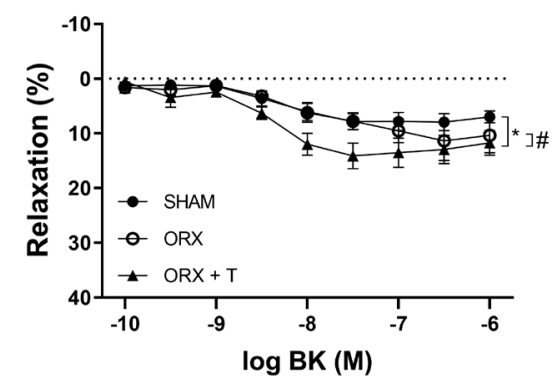

$\mathrm{F}$

L-NAME + INDO + TBA

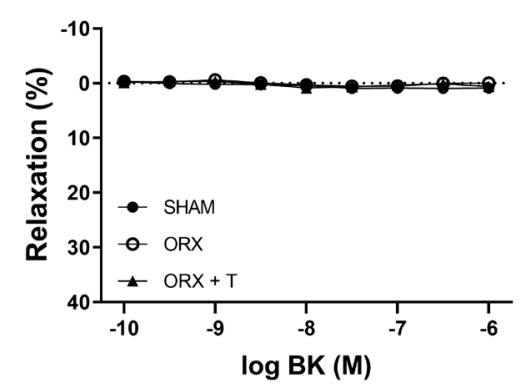

\section{Figure 3}

Dose-response curves to bradykinin in the coronary vascular bed of SHR. SHAM $(n=12)$ $\mathrm{ORX}(n=10), \mathrm{ORX}+\mathrm{T}(n=9)$ and $\mathrm{ORX}+\mathrm{T}+\mathrm{Al}(n=8)$ groups before $(A)$ and after infusion with L-NAME (B, $n=8)$; Indomethacin (INDO) $(\mathrm{C}, n=8)$; L-NAME + INDO (D, $n=8)$; L-NAME + INDO + Clotrimazole (CLOT) $(\mathrm{E}, n=8)$; L-NAME + INDO + Tetrabutylammonium (TBA) $(\mathrm{F}, n=8)$. Data were expressed as mean \pm S.E.M. Two-way ANOVA and Tukey's post-hoc tests were used. $* P<0.05$ vs SHAM; $\# P<0.05$ vs ORX.
(NO), arachidonic acid metabolites (EETs) and potassium channels participated substantially in this response.

Our results on blood pressure showed that orchiectomy prevented the progress of hypertension. These findings corroborate other studies (Masubuchi et al. 1982, Jenkins et al. 1994), suggesting an important role of testosterone in the increase of BP in SHR. In addition, orchiectomyinduced prostate and seminal glands' atrophy, suggesting that testosterone plays an important role in the function of these glands. Both results (BP and accessories gland atrophy) confirm our model of hypertension and hormonal deficiency. In relation to the baseline CPP, it was not altered by orchiectomy or testosterone treatment. Similar results in normotensive rats were obtained in our laboratory (Moysés et al. 2001, Rouver et al. 2015), suggesting that the testosterone does not modulate the baseline CPP in both normotensive and spontaneously hypertensive rats.

We analyzed coronary vascular reactivity in spite of no differences having been found in baseline CPP between groups. All groups showed BK-induced relaxation, which remained unaltered by orchiectomy. Treatment with testosterone for 15 days increased endotheliumdependent vasodilation induced by BK in the coronary vascular bed from orchiectomized SHR. This response was independent of aromatization. This response highlights a probable benefit of testosterone treatment in the coronary vascular bed from SHR. Similarly, Rouver et al. demonstrated that replacement therapy with testosterone increased relaxation to $\mathrm{BK}$ in the coronary circulation from normotensive rats (Rouver et al. 2015).

Following the endothelium-dependent vasodilation analysis, we assessed the participation of possible endothelial mediators involved in the relaxation response. After perfusion with the NO synthesis inhibitor, the vasodilator response to $\mathrm{BK}$ decreased in all groups, suggesting the participation, at least in part, of $\mathrm{NO}$ as an endothelium mediator in the coronary vascular bed. In the presence of the prostanoids synthesis inhibitor, 
A
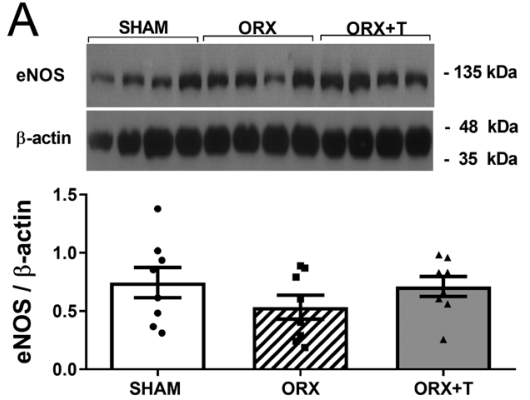

$\mathrm{RX}$
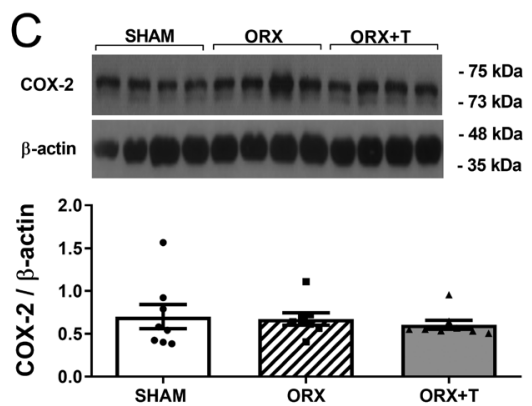

B

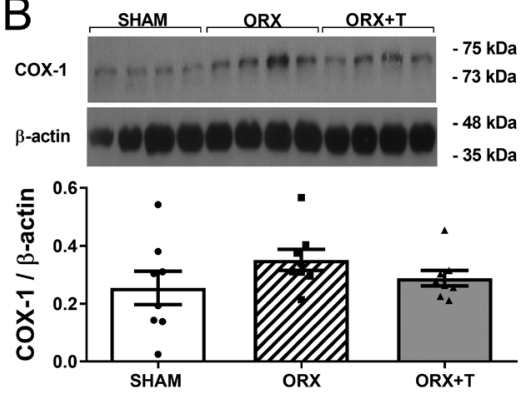

D

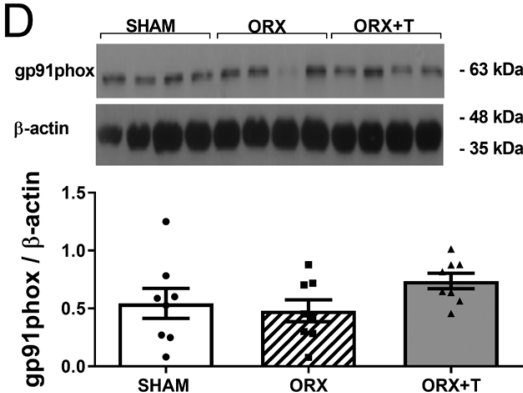

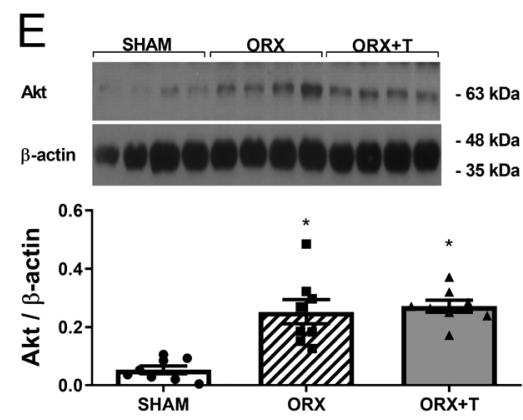

we observed a decrease in the relaxation to BK in SHAM and ORX animals, suggesting the participation of a vasodilator metabolite from the COX pathway, such as prostacyclin $\left(\mathrm{PGI}_{2}\right)$. In contrast, inhibition with indomethacin increased the relaxation to acetylcholine in SHR aorta (Luscher \& Vanhoutte 1986), which suggests the participation of a vasoconstrictor metabolite from the prostanoids pathway. These differences may occur due to the type of vessel studied. It has been reported that treatment with testosterone did not affect the synthesis of $\mathrm{PGI}_{2}$ in middle cerebral arteries from male rats (Gonzales et al. 2004), while it decreased the synthesis of $\mathrm{PGI}_{2}$ in rat aortic smooth muscle cells in culture (Nakao et al. 1981); pointing to the complexity of testosterone actions on the synthesis of prostanoids.

In SHAM and ORX groups, individual perfusion with L-NAME or INDO, or combined perfusion with L-NAME+INDO decreased relaxation to BK. This result suggests the independent participation of both $\mathrm{NO}$ or prostanoids metabolites in the coronary vascular bed of both groups. Nevertheless, in the ORX $+\mathrm{T}$ group, the perfusion with L-NAME or L-NAME+INDO decreased relaxation to $\mathrm{BK}$, whereas the perfusion with INDO did not modify the relaxation to $\mathrm{BK}$, suggesting the participation of $\mathrm{NO}$ in relaxation response to $\mathrm{BK}$ in the coronary vascular bed in the $\mathrm{ORX}+\mathrm{T}$ group. Moreover, perfusion with L-NAME+INDO+CLOT, almost abolished $\mathrm{BK}$ relaxation in all groups. It suggests also a participation of an endothelium mediator independent of the NOS and COX activity, such as metabolites of CYP, that is, EETs, in all groups. Similarly, a previous study from our laboratory demonstrated the participation of EETs in the relaxation to $\mathrm{BK}$ in the coronary bed of normotensive rats (Rouver $\mathrm{et}$ al. 2015). These metabolites of CYP, would act as possible candidates for endothelium-dependent hyperpolarization $(\mathrm{EDH})$ in the relaxation to BK in rat coronary artery, which were already mentioned by Fulton et al. (1995). Fisslthaler et al., in turn, indicated that 11,12-epoxyeicosatrienoic acid, 
a product of CYP 2C8/34, is essential in relaxation mediated by EDH in porcine coronary artery (Fisslthaler et al. 1999). It is known that a factor able to promotes EDH must exert endothelium-relation responses that does not are inhibits after the use of L-NAME or INDO but are inhibits by potassium channels blockers (Campbell \& Harder 2001). We also analyzed the participation of potassium channels, one of the main mediators of EDH. After perfusion with TBA, in the presence of L-NAME+INDO the relaxation to $\mathrm{BK}$ was almost abolished in all groups, suggesting the participation of potassium channels in the relaxation to BK in the coronary bed from SHR. Therefore, it seems that treatment with testosterone in the $\mathrm{ORX}+\mathrm{T}$ group positively modulates the participation of EDH (EETs stimulating potassium channels). It has been suggested a cross-talk between $\mathrm{NO}$ and $\mathrm{EDH}$, which could occur by an inhibitory (Nishikawa et al. 2000, Liu et al. 2002), stimulatory (Qiu \& Quilley 2001), synergistic (Cohen et al. 1997) or compensatory (Kilpatrick \& Cocks 1994) type. Also, several studies suggested that the main pathways of EDH (i.e. potassium channels) would be downregulated in SHR (Fujii et al. 1992, Weston et al. 2010). Thus, we suggest a possible cross-talk between $\mathrm{NO}$ and $\mathrm{EDH}$, since the participation of both $\mathrm{NO}$ and $\mathrm{EDH}$ was found in this study.

The expression of eNOS, COX-1, COX-2 and gp91phox (catalytic subunit of NADPH oxidase) were not altered among the groups, but the expression of Akt was increased in the ORX and ORX+T groups. It has been demonstrated the androgen modulation of NOS expression in vascular tissue of normotensive rats, where orchiectomy did not affect its expression in aorta (Blanco-Rivero et al. 2006a) and mesenteric artery (Blanco-Rivero et al. 2006b, 2007). However, the expression of neural NOS (nNOS), in the mesenteric artery, was reduced (Martín et al. 2005). On the other hand, in SHR, neither orchiectomy nor treatment with testosterone modified the expression of COX-1 and COX-2 but after perfusion with INDO, relaxation to BK decreased in the SHAM and ORX groups, which suggests that the activity of COX seems to be preserved. In other studies in normotensive rats, orchiectomy did not affect the expression of COX-2 in the mesenteric artery (Blanco-Rivero et al. 2006b), whereas it increases in aorta (Aina Martorell et al. 2008). Hence, testicular androgens would modulate the expression and function of COX in different ways, and would depend on the type of isoform, the type of vessel, and the disease.

We found that the expression of Akt was increased in the ORX group, what could not be prevented by testosterone treatment. It has been reported that orchiectomy decreases Akt expression and increases PI3K expression in the aorta of normotensive rats, leading to vascular inflammation (Zhao et al. 2016). We did not observe that pattern in our study, what could be the result of Akt expression being increased in order to indirectly minimize the effects of possible endothelial dysfunction in ORX groups.

Reactive oxygen species (ROS) can affect vascular relaxation (Liu et al. 2002). In males, testosterone activates NADPH oxidase via renin angiotensin system (RAS) (Fischer et al. 2002), leading to increased synthesis of ROS, that is, superoxide anion $\left(\mathrm{O}_{2} \cdot{ }^{-}\right)$(Chignalia et al. 2012). The $\mathrm{O}_{2} \cdot^{-}$reacts rapidly with $\mathrm{NO}$ (reducing its bioavailability), forming peroxynitrite $\left(\mathrm{ONOO}^{-}\right)$, which impairs the vasodilation mediated by EDH (Liu et al. 2002). In this context, the expression of the gp91phox subunit of NADPH oxidase was analyzed, which was not different between the groups, which suggests that testosterone does not modulate its expression in the coronary vascular bed from male SHR.

Finally, treatment with testosterone increased the relaxing response to $\mathrm{BK}$ in the coronary bed of orchiectomized SHR, with the participation of NO and EETs. This may be due to the fact find in our study that testosterone, in the absence of others testicular androgens, could modulates the coronary vascular reactivity by the following mechanisms: mainly by a probable upregulation of the synthesis and activity of CYP metabolites (EETs) and their action in potassium channels, and by an improvement in NO bioavailability, which would allow the modulation of a probable cross-talk between $\mathrm{NO}$ and $\mathrm{EDH}$.

\section{Conclusions}

Although treatment with testosterone did not reduce blood pressure, it led to increased endothelium-dependent relaxation in the coronary vascular bed of spontaneously hypertensive orchiectomized rats. This effect appears to be independent of aromatase activity and to involve the participation of $\mathrm{NO}$ and arachidonic acid metabolites (i.e. EETs). Our results point to the androgen having a regional impact. This work unveils the important participation of EETs and potassium channels in the coronary circulation of hypertensive rats. The characterization of these mechanisms could lead to a better understanding of the role played by testosterone, especially in the coronary vascular bed under hypertensive conditions.

\section{Declaration of interest}

The authors declare that there is no conflict of interest that could be perceived as prejudicing the impartiality of the research reported. 


\section{Funding}

This work was supported by CAPES.

\section{Author contribution statement}

JC Arapa-Diaz and WN Rouver involved in acquisition of data and substantial contributions to conception and design; analysis and interpretation of data; drafting the article; revising it critically for important intellectual content; and final approval of the version to be published. MD Grando involved in acquisition of data. LM Bendhack and JAS Giesen and RL Santos involved in substantial contributions to conception and design; analysis and interpretation of data; drafting the article; revising it critically for important intellectual content; and final approval of the version to be published.

\section{References}

Adams MR, Williams JK \& Kaplan JR 1995 Effects of androgens on coronary artery atherosclerosis and atherosclerosis-related impairment of vascular responsiveness. Arteriosclerosis, Thrombosis, and Vascular Biology 15 562-570. (https://doi.org/10.1161/01.ATV.15.5.562)

Altintas D, Kokcu A, Kandemir B, Tosun M \& Cetinkaya MB 2010 Comparison of the effects of raloxifene and anastrozole on experimental endometriosis. European Journal of Obstetrics, Gynecology, and Reproductive Biology 150 84-87. (https://doi. org/10.1016/j.ejogrb.2010.02.004)

Bell RM, Mocanu MM \& Yellon DM 2011 Retrograde heart perfusion: the Langendorff technique of isolated heart perfusion. Journal of Molecular and Cellular Cardiology 50 940-950. (https://doi. org/10.1016/j.yjmcc.2011.02.018)

Benjamin EJ, Virani SS, Callaway CW, Chamberlain AM, Chang AR, Cheng S, Chiuve SE, Cushman M, Delling FN, Deo R, et al. 2018 Heart disease and stroke statistics-2018 update: a report from the American Heart Association. Circulation 137 e67-e492. (https://doi. org/10.1161/CIR.0000000000000558)

Blanco-Rivero J, Sagredo A, Balfagón G \& Ferrer M $2006 a$ Orchidectomy increases expression and activity of $\mathrm{Cu} / \mathrm{Zn}$-superoxide dismutase, while decreasing endothelial nitric oxide bioavailability. Journal of Endocrinology 190 771-778. (https://doi.org/10.1677/ joe.1.06887)

Blanco-Rivero J, Balfagón G \& Ferrer M 2006b Orchidectomy modulates $\alpha_{2}$-adrenoceptor reactivity in rat mesenteric artery through increased thromboxane $\mathrm{A}_{2}$ formation. Journal of Vascular Research 43 101-108. (https://doi.org/10.1159/000089791)

Blanco-Rivero J, Sagredo A, Balfagón G \& Ferrer M 2007 Protein kinase $\mathrm{C}$ activation increases endothelial nitric oxide release in mesenteric arteries from orchidectomized rats. Journal of Endocrinology 192 189-197. (https://doi.org/10.1677/joe.1.07079)

Bucci M, Mirone V, Di Lorenzo A, Vellecco V, Roviezzo F, Brancaleone V, Ciro I \& Cirino G 2009 Hydrogen sulphide is involved in testosterone vascular effect. European Urology $\mathbf{5 6}$ 378-383. (https://doi.org/10.1016/j.eururo.2008.05.014)

Buvat J, Maggi M, Guay A \& Torres LO 2013 Testosterone deficiency in men: systematic review and standard operating procedures for diagnosis and treatment. Journal of Sexual Medicine 10 245-284. (https://doi.org/10.1111/j.1743-6109.2012.02783.x)

Campbell WB \& Harder DR 2001 Prologue: EDHF-what is it? American Journal of Physiology: Heart and Circulatory Physiology $\mathbf{2 8 0}$ H2413-H2416. (https://doi.org/10.1152/ajpheart.2001.280.6.H2413)

Chignalia AZ, Schuldt EZ, Camargo LL, Montezano AC, Callera GE, Laurindo FR, Lopes LR, Avellar MCW, Carvalho MHC, Fortes ZB, et al. 2012 Testosterone induces vascular smooth muscle cell migration by NADPH oxidase and c-Src-dependent pathways. Hypertension 59 1263-1271. (https://doi.org/10.1161/ HYPERTENSIONAHA.111.180620)
Chobanian AV, Bakris GL, Black HR, Cushman WC, Green LA, Izzo JLJ, Jones DW, Materson BJ, Oparil S, Wright JTJ, et al. 2003 The seventh report of the Joint National Committee on prevention, detection, evaluation, and treatment of high blood pressure: the JNC 7 report. JAMA 289 2560-2572. (https://doi.org/10.1001/ jama.289.19.2560)

Cohen RA, Plane F, Najibi S, Huk I, Malinski T \& Garland CJ 1997 Nitric oxide is the mediator of both endothelium-dependent relaxation and hyperpolarization of the rabbit carotid artery. PNAS 94 4193-4198. (https://doi.org/10.1073/pnas.94.8.4193)

Deenadayalu VP, White RE, Stallone JN, Gao X \& Garcia AJ 2001 Testosterone relaxes coronary arteries by opening the largeconductance, calcium-activated potassium channel. American Journal of Physiology: Heart and Circulatory Physiology 281 H1720-H1727. (https://doi.org/10.1152/ajpheart.2001.281.4.H1720)

Deenadayalu V, Puttabyatappa Y, Liu AT, Stallone JN \& White RE 2012 Testosterone-induced relaxation of coronary arteries: activation of BK Ca channels via the cGMP-dependent protein kinase. American Journal of Physiology: Heart and Circulatory Physiology 302 H115-H123. (https://doi.org/10.1152/ajpheart.00046.2011)

Dregan A, Stewart R \& Gulliford MC 2013 Cardiovascular risk factors and cognitive decline in adults aged 50 and over: a population-based cohort study. Age and Ageing 42 338-345. (https://doi.org/10.1093/ ageing/afs166)

Farhat MY, Lavigne MC \& Ramwell PW 1996 The vascular protective effects of estrogen. FASEB Journal 10 615-624. (https://doi. org/10.1096/fasebj.10.5.8621060)

Fischer M, Baessler A \& Schunkert H 2002 Renin angiotensin system and gender differences in the cardiovascular system. Cardiovascular Research 53 672-677. (https://doi.org/10.1016/S00086363(01)00479-5)

Fisslthaler B, Popp R, Kiss L, Potente M, Harder DR, Fleming I \& Busse R 1999 Cytochrome P450 2C is an EDHF synthase in coronary arteries. Nature 401 493-497. (https://doi.org/10.1038/46816)

Fritz M \& Rinaldi G 2008 Blood pressure measurement with the tailcuff method in Wistar and spontaneously hypertensive rats: influence of adrenergic- and nitric oxide-mediated vasomotion. Journal of Pharmacological and Toxicological Methods 58 215-221. (https://doi.org/10.1016/j.vascn.2008.08.002)

Fujii K, Tominaga M, Ohmori S, Kobayashi K, Koga T, Takata Y \& Fujishima M 1992 Decreased endothelium-dependent hyperpolarization to acetylcholine in smooth muscle of the mesenteric artery of spontaneously hypertensive rats. Circulation Research 70 660-669. (https://doi.org/10.1161/01.res.70.4.660)

Fulton D, Mahboubi K, McGiff JC \& Quilley J 1995 Cytochrome P450-dependent effects of bradykinin in the rat heart. British Journal of Pharmacology 114 99-102. (https://doi. org/10.1111/j.1476-5381.1995.tb14911.x)

Gonzales RJ, Krause DN \& Duckles SP 2004 Testosterone suppresses endothelium-dependent dilation of rat middle cerebral arteries. American Journal of Physiology: Heart and Circulatory Physiology 286 H552-H560. (https://doi.org/10.1152/ajpheart.00663.2003)

Haring R, John U, Völzke H, Nauck M, Dörr M, Felix SB \& Wallaschofski H 2012 Low testosterone concentrations in men contribute to the gender gap in cardiovascular morbidity and mortality. Gender Medicine 9 557-568. (https://doi.org/10.1016/j. genm.2012.10.007)

Ibrahim J, Berk BC \& Hughes AD 2006 Comparison of simultaneous measurements of blood pressure by tail-cuff and carotid arterial methods in conscious spontaneously hypertensive and Wistar-Kyoto rats. Clinical and Experimental Hypertension 28 57-72. (https://doi. org/10.1080/10641960500386817)

James PA, Oparil S, Carter BL, Cushman WC, Dennison-Himmelfarb C, Handler J, Lackland DT, LeFevre ML, MacKenzie TD, Ogedegbe O, et al. 20142014 Evidence-based guideline for the management of high blood pressure in adults: report from the panel members 
appointed to the Eighth Joint National Committee (JNC 8). JAMA

311 507-520. (https://doi.org/10.1001/jama.2013.284427)

Jenkins C, Salisbury R \& Ely D 1994 Castration lowers and testosterone restores blood pressure in several rat strains on high sodium diets. Clinical and Experimental Hypertension 16 611-625. (https://doi.org/10.3109/10641969409067965)

Jones RD, English KM, Jones TH \& Channer KS 2004 Testosteroneinduced coronary vasodilatation occurs via a non-genomic mechanism: evidence of a direct calcium antagonism action. Clinical Science 107 149-158. (https://doi.org/10.1042/CS20030386)

Kilpatrick EV \& Cocks TM 1994 Evidence for differential roles of nitric oxide (NO) and hyperpolarization in endothelium-dependent relaxation of pig isolated coronary artery. British Journal of Pharmacology 112 557-565. (https://doi.org/10.1111/j.1476-5381.1994.tb13110.x)

Liu Y, Terata K, Chai Q, Li H, Kleinman LH \& Gutterman DD 2002 Peroxynitrite inhibits Ca2+-activated $\mathrm{K}+$ channel activity in smooth muscle of human coronary arterioles. Circulation Research $\mathbf{9 1}$ 1070-1076. (https://doi.org/10.1161/01.RES.0000046003.14031.98)

Luscher TF \& Vanhoutte PM 1986 Endothelium-dependent contractions to acetylcholine in the aorta of the spontaneously hypertensive rat. Hypertension 8 344-348. (https://doi. org/10.1161/01.HYP.8.4.344)

MacMahon S, Peto R, Cutler J, Collins R, Sorlie P, Neaton J, Abbott R, Godwin J, Dyer A \& Stamler J 1990 Blood pressure, stroke, and coronary heart disease. Part 1, prolonged differences in blood pressure: prospective observational studies corrected for the regression dilution bias. Lancet 335 765-774. (https://doi. org/10.1016/0140-6736(90)90878-9)

Mangelsdorf DJ \& Evans RM 1995 The RXR heterodimers and orphan receptors. Cell 83 841-850. (https://doi.org/10.1016/00928674(95)90200-7)

Mark Herman SM, Robinson JTC, McCredie RJ, Adams MR, Boyer MJ \& Celermajer DS 1997 Androgen deprivation is associated with enhanced endothelium-dependent dilatation in adult men. Arteriosclerosis, Thrombosis, and Vascular Biology 17 2004-2009. (https://doi.org/10.1161/01.atv.17.10.2004)

Martín MC, Balfagón G, Minoves N, Blanco-Rivero J \& Ferrer M 2005 Androgen deprivation increases neuronal nitric oxide metabolism and its vasodilator effect in rat mesenteric arteries. Nitric Oxide: Biology and Chemistry 12 163-176. (https://doi.org/10.1016/j.niox.2005.02.003)

Martorell A, Blanco-Rivero J, Aras-López R, Sagredo A, Balfagón G \& Ferrer M 2008 Orchidectomy increases the formation of prostanoids and modulates their role in the acetylcholine-induced relaxation in the rat aorta. Cardiovascular Research 77 590-599. (https://doi. org/10.1093/cvr/cvm059)

Masubuchi Y, Kumai T, Uematsu A, Komoriyama K \& Hirai M 1982 Gonadectomy-induced reduction of blood pressure in adult spontaneously hypertensive rats. Acta Endocrinologica 101 154-160. (https://doi.org/10.1530/acta.0.1010154)

Moazed B, Quest D \& Gopalakrishnan V 2009 Des-acyl ghrelin fragments evoke endothelium-dependent vasodilatation of rat mesenteric vascular bed via activation of potassium channels. European Journal of Pharmacology 604 79-86. (https://doi. org/10.1016/j.ejphar.2008.10.032)

Montaño LM, Calixto E, Figueroa A, Flores-Soto E, Carbajal V \& Perusquía M 2008 Relaxation of androgens on rat thoracic aorta: testosterone concentration dependent agonist/antagonist L-type $\mathrm{Ca} 2+$ channel activity, and $5 \beta$-dihydrotestosterone restricted to L-type Ca2+ channel blockade. Endocrinology 149 2517-2526. (https://doi.org/10.1210/en.2007-1288)
Moysés MR, Barker LA \& Cabral AM 2001 Sex hormone modulation of serotonin-induced coronary vasodilation in isolated heart. Brazilian Journal of Medical and Biological Research 34 949-958. (https://doi.org/10.1590/S0100-879X2001000700014)

Nakao J, Chang WC, Murota SI \& Orimo H 1981 Testosterone inhibits prostacyclin production by rat aortic smooth muscle cells in culture. Atherosclerosis 39 203-209. (https://doi.org/10.1016/00219150(81)90070-8)

Nishikawa Y, Stepp DW \& Chilian WM 2000 Nitric oxide exerts feedback inhibition on EDHF-induced coronary arteriolar dilation in vivo. American Journal of Physiology: Heart and Circulatory Physiology 279 H459-H465. (https://doi.org/10.1152/ ajpheart.2000.279.2.H459)

Qiu Y \& Quilley J 2001 Apamin/charybdotoxin-sensitive endothelial $\mathrm{K}+$ channels contribute to acetylcholine-induced, NO-dependent vasorelaxation of rat aorta. Medical Science Monitor 7 1129-1136.

Rouver WN, Delgado NTB, Menezes JB, Santos RL \& Moyses MR 2015 Testosterone replacement therapy prevents alterations of coronary vascular reactivity caused by hormone deficiency induced by castration. PLoS ONE $\mathbf{1 0}$ e0137111. (https://doi.org/10.1371/ journal.pone.0137111)

Santos RL, Marin EB, Gonçalves WLS, Bissoli NS, Abreu GR \& Moysés MR 2010 Sex differences in the coronary vasodilation induced by $17 \beta$-oestradiol in the isolated perfused heart from spontaneously hypertensive rats. Acta Physiologica 200 203-210. (https://doi.org/10.1111/j.1748-1716.2010.02140.x)

Shores MM, Smith NL, Forsberg CW, Anawalt BD \& Matsumoto AM 2012 Testosterone treatment and mortality in men with low testosterone levels. Journal of Clinical Endocrinology and Metabolism 97 2050-2058. (https://doi.org/10.1210/jc.2011-2591)

Svartberg J, von Mühlen D, Schirmer H, Barrett-Connor E, Sundfjord J \& Jorde R 2004 Association of endogenous testosterone with blood pressure and left ventricular mass in men. The Tromsø Study. European Journal of Endocrinology 150 65-71. (https://doi. org/10.1530/eje.0.1500065)

Vasan RS, Larson MG, Leip EP, Evans JC, O'Donnell CJ, Kannel WB \& Levy D 2001 Impact of high-normal blood pressure on the risk of cardiovascular disease. New England Journal of Medicine $\mathbf{3 4 5}$ 1291-1297. (https://doi.org/10.1056/NEJMoa003417)

Vigen R, O'Donnell CI, Barón AE, Grunwald GK, Maddox TM, Bradley SM, Barqawi A, Woning G, Wierman ME, Plomondon ME, et al. 2013 Association of testosterone therapy with mortality, myocardial infarction, and stroke in men with low testosterone levels. JAMA 310 1829-1836. (https://doi.org/10.1001/ jama.2013.280386)

Weston AH, Porter EL, Harno E \& Edwards G 2010 Impairment of endothelial SK Ca channels and of downstream hyperpolarizing pathways in mesenteric arteries from spontaneously hypertensive rats. British Journal of Pharmacology 160 836-843. (https://doi. org/10.1111/j.1476-5381.2010.00657.x)

Zhao J, Liu GL, Wei Y, Jiang LH, Bao PL \& Yang QY 2016 Low-dose testosterone alleviates vascular damage caused by castration in male rats in puberty via modulation of the PI3K/AKT signaling pathway. Molecular Medicine Reports 14 2518-2526. (https://doi.org/10.3892/ mmr.2016.5562)

Zhou P, Fu L, Pan Z, Ma D, Zhang Y, Qu F, Guo L, Cao J, Gao Q \& Han Y 2008 Testosterone deprivation by castration impairs expression of voltage-dependent potassium channels in rat aorta. European Journal of Pharmacology 593 87-91. (https://doi. org/10.1016/j.ejphar.2008.07.014)

Received in final form 5 August 2020

Accepted 3 September 2020

Accepted Manuscript published online 4 September 2020
(C) 2020 Society for Endocrinology Published by Bioscientifica Ltd. Printed in Great Britain 